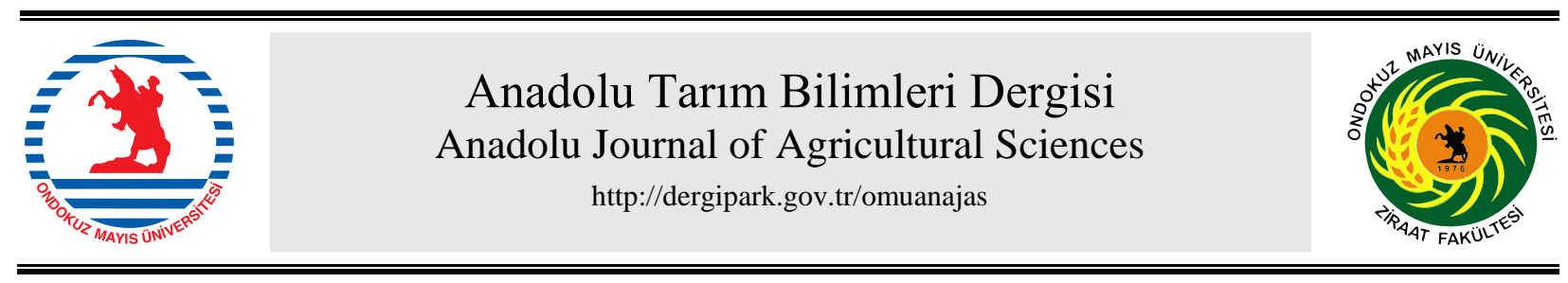

Araştırma/Research

Anadolu Tarım Bilim. Derg./Anadolu J Agr Sci, 34 (2019) ISSN: 1308-8750 (Print) 1308-8769 (Online) doi: 10.7161/omuanajas.469441

\title{
Karayemişte bazı bitki özellikleri üzerine boğma ve Pro-Ca uygulamalarının etkisi
}

\author{
Ali İslam*, Orhan Karakaya, Hale Orta, Burhan Öztürk \\ ${ }^{a}$ Ordu Üniversitesi Ziraat Fakültesi Bahçe Bitkileri Bölümü, Ordu \\ *Sorumlu yazar/corresponding author: islamali@ hotmail.com
}

Geliş/Received 11/10/2018 Kabul/Accepted 24/01/2019

\begin{abstract}
ÖZET
Bu çalışma karayemişte (Prunus laurocerasus L.) taç yüksekliği, taç genişliği, sürgün uzunluğu, gövde çap1, yaprak üst sıcaklığ1, yaprak alt sıcaklığı ve yaprak klorofil miktarı üzerine boğma ve Pro-Ca (prohexadione-calcium) uygulamalarının etkisini belirlemek amacı ile 2015-2016 yıllarında yürütülmüştür. Çalışmada materyal olarak Ordu Üniversitesi Ziraat Fakültesi Uygulama ve Araştırma Arazisinde bulunan 4 yaşlı karayemiş genotipleri kullanılmıştır. Pro-Ca uygulaması her iki yılda da 15 Mayıs ve 20 Temmuz tarihlerinde 500 ppm dozunda ağaçların taç kısmı tamamen sslanacak şekilde sprey olarak uygulanmıştır. Boğma uygulaması 7 Mayıs tarihinde ağaçların gövdesine toprak seviyesinden $15 \mathrm{~cm}$ yukarıda bir kelepçe yardımı ile yapılmıştır. Çalışmada vejetasyon süresince 15 günlük periyotlarla ölçüm işlemi gerçekleştirilmiştir. Çalışma sonucunda taç yüksekliği $244 \mathrm{~cm}$ (Pro-Ca ve boğma) ile $245 \mathrm{~cm}$ (kontrol), taç genişliği $163 \mathrm{~cm}$ (kontrol) ile $177 \mathrm{~cm}$ (Pro-Ca) arasında belirlenmiştir. En yüksek gövde çap1 $60.40 \mathrm{~mm}$ olarak Pro-Ca uygulamasında ölçülürken, en düşük $51.19 \mathrm{~mm}$ ile kontrol uygulamasında ölçülmüştür. En yüksek sürgün uzunluğu boğma uygulamasında $(51.49 \mathrm{~cm})$, en düşük ise Pro-Ca uygulamasında $(47.90 \mathrm{~cm})$ belirlenmiştir. Yaprak üst sıcaklığ $122.91{ }^{\circ} \mathrm{C}$ (Pro-Ca) - $24.51{ }^{\circ} \mathrm{C}$ (kontrol), yaprak alt sıcaklığ 1 ise $22.53{ }^{\circ} \mathrm{C}$ (Pro-Ca) - $24.02{ }^{\circ} \mathrm{C}$ (kontrol) arasında ölçülmüştür. En yüksek klorofil miktarı 98.88 olarak Pro-Ca uygulamsında ölçülürken, en düşük ise 92.15 ile boğma uygulamasında ölçülmüştür. Sonuç olarak, Pro-Ca uygulamasının karayemişte vejetatif gelişimi sınırlandırmada daha etkili olduğu belirlenmiştir.
\end{abstract}

\section{Effects of girdling and Pro-Ca applications on some plant characteristics in Cherry Laurel}

This study was carried out to determine the effects of girdling and Pro-Ca (prohexadione-calcium) application on canopy height, canopy width, shoot length, trunk diameter, leaf top temperature, leaf bottom temperature and amount of chlorophyll in leaf in cherry laurel (Prunus laurocerasus L.), in 2015 and 2016 years. In the study, cherry laurel genotypes in Application and Research Area of University of Ordu were used as a material. $500 \mathrm{ppm}$ Pro-Ca was sprayed by means completely wet the canopy of trees in both 15 May and 20 July. Girdling application was made using plastic clamp the trunk of trees on 7 May. Measures in the implemented trees were made at 15 days interval during vegetation. The result of study, canopy height was determined between $244 \mathrm{~cm}$ (Pro-Ca and girdling applications) and $245 \mathrm{~cm}$ (Control). Canopy width was determined between $163 \mathrm{~cm}$ (Control) and 177 $\mathrm{cm}$ (Pro-Ca application). While the highest trunk diameter was measured as $60.40 \mathrm{~mm}$ in Pro-Ca application, the lowest was measured as $51.19 \mathrm{~mm}$ in control application. The highest shoot length was determined in girdling application $(51.49 \mathrm{~cm})$, the lowest was determined in Pro-Ca application (47.90 $\mathrm{cm}$ ). Leaf top temperature measured between $22.91{ }^{\circ} \mathrm{C}$ (Pro-Ca application) and $24.51{ }^{\circ} \mathrm{C}$ (Control). Leaf bottom temperature measured between $22.53{ }^{\circ} \mathrm{C}$ (Pro-Ca application) and $24.02{ }^{\circ} \mathrm{C}$ (Control). While the highest amount of chlorophyll in leaf was measured as 98.88 in Pro-Ca application, the lowest was measured as $92.15 \mathrm{~mm}$ in girdling application. As a conclusion, Pro-Ca application was determined to be better effective on the vegetative growth in cherry laurel.
Anahtar Sözcükler:

Prunus laurocerasus

Sürgün uzunluğu

Gövde çap1

Yaprak sicaklığ 1

Klorofil

Keywords:

Prunus laurocerasus

Shoot length

Trunk diameter

Leaf temperature

Chlorophyll

(C) OMU ANAJAS 2019 


\section{Giriş}

Karayemiş Rosaceae familyası içerinde yer alan sert çekirdekli bir meyve türüdür (İslam, 2005). Dünya üzerinde Orta ve Batı Asya, Güneydoğu Avrupa ve Anadolu'da doğal olarak yayılış göstermektedir (Ansin ve Özkan, 1998). Ülkemizde özellikle Doğu Karadeniz Bölgesi'nde doğal olarak yetişen bir meyve türüdür. Bölgede genel olarak ev bahçelerinde veya findık bahçelerinde sınır bitkisi olarak yetiştirilmektedir (Karadeniz ve Kalkışım, 1996; Bostan ve İslam, 2003). $\mathrm{Bu}$ meyve türünün (Karayemişin) bölgede var olan genetik kaynaklarının ortaya çıkarılması amacı yapılmış birçok seleksiyon çalıșmaları bulunmaktadır (Bostan ve İslam 2003; Akbulut ve ark., 2007; İslam ve ark., 2010; Macit ve Demirsoy, 2012; İslam ve Deligöz, 2012). Bu çalışmalar neticesinde son yıllarda ticari değeri artan ve popüler bir meyve türü olan karayemiş̧e çeşit adayı olabilecek ümitvar genotipler ortaya çıkarılmıştır.

Meyve yetiştiriciliğinde olumsuz iklim koşulları, kültürel uygulamaların yetersiz ve bilinçsiz yapılması ve kullanılan çeşidin büyüme gücünün fazla olması gibi nedenlerden dolayı ağaçlarda vejetatif gelişim ile generatif gelişim arasındaki denge bozulmaktadır. Genel olarak bu durum vejetaif gelişim lehine olmaktadır. Fizyolojik dengenin bozulması sonucunda ağaçlar yeterince çiçek tomurcuğu oluşturamamakta ve çok fazla sürgün meydana getirmektedir. Ayrıca meyve kalitesi de düşmektedir. Günümüzde vejetatif gelişimin sınırlandırılması amacı ile çeşitli uygulamalar ve kimyasallar kullanılmaktadır (Çağlar ve Ağca, 2009). $\mathrm{Bu}$ amaçla meyve ağaçlarında boğma (Sousa ve ark., 2008), bilezik alma, dal eğme (Özçağıran, 1974; Ağca, 2008) ve Prohexadione-calcium (Çağlar ve Ağca, 2009; Hekimci, 2014) uygulamaları yapılmaktadır.

Boğma uygulaması meyve ağaçlarında vejetatif gelişimin sınırlandırılması, çiçek tomurcuğu teşekkülü, meyve tutumu ve meyve iriliğinin arttırılması için kullanılan etkili bir tekniktir (Pretorius ve ark., 2004). Boğma uygulaması fotosentez sonucunda yapraklarda üretilen karbonhidratın köklere aşınımını azaltmakta ve böylece vejetatif gelişimi sınırlandırarak çiçek tomurcuğu teșekkülünü arttırmaktadır (Marafon ve ark., 2008). Yapılan çalışmalarda boğma uygulamasının armutta (Iuchi ve ark., 2008), elmada (Pretorius ve ark., 2004), cevizde (Sabancı ve Çağlar, 2005) ve bademde (Alkan ve Seferoğlu, 2014) vejetatif gelişimi sınırlandırdığını bildirilmiştir.

Prohexadione-calcium (Pro-Ca) meyve ağaçlarında sürgün gelişimini sınırlandırarak vejetatif gelişim ile generatif gelişim arasında dengeyi sağlamaktadır. Pro$\mathrm{Ca}$ bir gibberellik asit inhibitörüdür. Pro-Ca genel olarak elma ve armut yetiştiriciliğinde kullanılmaktadır (Evans ve ark., 1997). Bu meyve türlerinde sürgün gelişimini sınırlandırmasının yanı sıra özellikle ateş yanıklığı hastalığı üzerine etki ettiği bildirilmektedir (Baştaş ve Maden, 2004; Costa ve ark., 2004). Yapılan çalışmalarda Pro-Ca uygulamasının elmada (Medjdoub ve ark,. 2004), armutta (Smit ve ark., 2005) ve kirazda
(Elfving ve ark., 2005) sürgün gelişimini azalttığ bildirilmiştir.

$\mathrm{Bu}$ çalışma karayemişte vejetatif gelişim üzerine boğma ve Pro-Ca uygulamalarının etkisini belirlenmek amacı ile yürütülmüştür.

\section{Materyal ve Yöntem}

Çalı̧̧manın materyalini TÜBITTAK projesi kapsamında Doğu Karadeniz Bölgesi'nden seçilen karayemiş genotipleri oluşturmuş̧ur. Çalışmada materyal olarak kullanılan karayemiş genotipleri çelikle çoğaltılmıştır. Çalışma Ordu Üniversitesi Ziraat Fakültesi Uygulama ve Araştırma Arazisi'nde 2011 yılında kurulmuş kapama karayemiş bahçesinde 20152016 yıllarında yürütülmüştür.

Çalışma Tesadüf Parselleri Deneme Desenine göre 3 tekerürlü ve her tekerrürde 1 ağaç olacak şekilde kurulmuştur. Çalışmada 500 ppm dozunda Pro-Ca (Regalis, \% 10 aktif madde), her iki yılda da 15 Mayıs ve 20 Temmuz tarihlerinde ağaçların taç kısmı tamamen sslanacak şekilde sabah erken saatlerde ve rüzgarsı bir havada sprey olarak uygulanmıştır. Boğma uygulaması ise vejetasyon başlangıcında (7 Mayıs tarihinde) ağaçların gövdesine toprak seviyesinden $15 \mathrm{~cm}$ yukarıda $30 \mathrm{~cm}$ uzunluğunda plastik kelepçe kullanılarak yapılmıştır. Uygulama yapılan ağaçlarda ölçümler 15 günlük periyotlar ile vejetasyon sonuna kadar yapılmıştır. Çalışmada taç yüksekliği, taç genişliği, gövde çap1, sürgün uzunluğu, yaprak alt ve üst sıcaklığı ve yaprak klorofil miktarı parametreleri 2 y1l süre ile incelenmiş ve ortalama değerler sunulmuştur.

\subsection{Taç yüksekliği (cm)}

Her uygulamada yer alan ağaçlarda vejetasyon süresi sonunda dallanmanın ilk başladığı nokta ile ağacın tepe noktası arasındaki mesafenin şerit metre yardımı ile ölçülmesiyle belirlenmiştir (Westwood, 1978).

\subsection{Taç genişliği $(\mathrm{cm})$}

Her uygulamada yer alan ağaçlarda vejetasyon süresi sonunda tacın her iki yanındaki sürgünlerin en uç noktası arasındaki mesafenin şerit metre yardımı ile ölçülmesiyle belirlenmiştir (Westwood, 1978).

\subsection{Gövde çapı (mm)}

Kontrol ve Pro-Ca uygulanmış ağaçlarda toprak seviyesinden $20 \mathrm{~cm}$ yukarıda, boğma uygulaması yapılan ağaçlarda ise boğmanın yapıldığ 1 yerin $5 \mathrm{~cm}$ üzerinde her iki yılın vejetasyon başlangıcı ve sonunda kumpas yardımı ile gövdenin iki yönlü olarak ölçülmesi ile belirlenmiştir (Pearce, 1975). 


\subsection{Sürgün uzunluğu (cm)}

Her uygulamaya ait ağaçlarda seçilen 3'er sürgünde her iki yılın vejetasyon başlangıcı ve sonunda cetvel kullanılarak ölçülmüştür (Ağca, 2008).

\subsection{Yaprak slcaklı̆ $\breve{l}\left({ }^{\circ} \mathrm{C}\right)$}

Yaprak sıcaklığı infrared termometre kullanılarak yaprağın alt ve üst yüzeylerinde ölçülmüştür.

\subsection{Yaprak klorofil miktarı (SPAD)}

Klorofil miktarı SPAD metre (SPAD-502, Minolta, Japan) kullanılarak her tekerrürde bulunan ağaçlara ait 6 adet yaprakta ölçülmüştür.

\subsection{Istatistiksel değerlendirme}

Verilerin değerlendirilmesinde SPSS 23.0 istatistik paket programı kullanılmıştır. Ortalamalar arasındaki farklılık Tukey çoklu karşılaştırma yöntemine göre belirlenmiştir.

\section{Bulgular ve Tartış̧ma}

Çalışma karayemiş meyve türünde taç yüksekliği, taç genişliği, gövde çapı, sürgün uzunluğu, yaprak alt ve üst sıcaklığı ve yaprak klorofil miktarı parametreleri üzerine boğma ve Pro-Ca uygulamalarının etkisini belirlemek amacı ile iki yıl süre ile (2015-2016) yürütülmüştür. Çalışmada her iki yılda da incelenen özelliklere ait değerlerin ortalaması sunulmuştur.

Taç yüksekliği ve taç genişliği bakımından uygulamalar arasında istatistiksel olarak bir farkl1l1k belirlenmemiştir ( $p>0.05)$. En yüksek taç yüksekliği 257 $\mathrm{cm}$ ile Pro-Ca uygulamasında belirlenirken, en düşük ise $240 \mathrm{~cm}$ ile kontrol uygulamasında belirlenmiştir. En yüksek taç genişliği Pro-Ca uygulamasında $(180 \mathrm{~cm})$, en düşük ise kontrol uygulamasında $(170 \mathrm{~cm})$ ölçülmüsşür (Çizelge 1). Çağlar ve Ağca (2009) elmada Pro-Ca uygulamasının ağaç boyu üzerine etkisinin önemsiz olduğunu, taç genişliğini ise önemli ölçüde azalttığını belirlemişlerdir. Çetinbaş ve ark. (2014) Scarlet Spur elma çeşidinde Pro-Ca uygulamasının ağaç boyu ve taç genişliği üzerine etkili olmadığını tespit etmiş̧lerdir. Rufato ve ark. (2015), armutta boğma uygulamasının taç hacmi ve taç gelişimini azalttığını tespit etmişlerdir. Elde ettiğimiz bulgular genel olarak araştırıcıların bulguları ile benzerlik gösterirken, görülen bazı farklılıkların ise meyve türünden kaynaklı olabileceği düşünülmektedir.

Çalışmada gövde çapı bakımından uygulamalar arasındaki farklılık istatistiksel olarak önemli bulunmuştur $(p<0.05)$. En yüksek gövde çapı Pro-Ca uygulamasinda $(60.40 \mathrm{~mm})$, en düşük ise kontrol uygulamasında $(51.19 \mathrm{~mm})$ tespit edilmiştir (Çizelge 1). Medjdoub ve ark. (2004), elmada gövde çapı gelişimi üzerine Pro-Ca uygulamasının etkisinin olmadığını belirlemiştir. Çetinbaş ve ark. (2014) Scarlet Spur elma çeşidinde Pro-Ca uygulamasının gövde çapı üzerine etkili olmadığını tespit etmişlerdir. Rufato ve ark. (2015) armutta boğma uygulamasının gövde çapını azalttığını belirlemişlerdir. Gövde çapı bakımından elde edilen bulgular araştırıcıların bulguları benzerlik göstermektedir.

Çizelge 1. Karayemişte farklı uygulamaların morfolojik özellikler üzerine etkisi (2015-2016 y1lları ortalamasi)

\begin{tabular}{lllll}
\hline Uygulama & $\begin{array}{l}\text { Taç } \\
\text { Yüksekliği } \\
(\mathrm{cm})\end{array}$ & $\begin{array}{l}\text { Taç } \\
\text { Genişliği } \\
(\mathrm{cm})\end{array}$ & $\begin{array}{l}\text { Gövde } \\
\text { Çap1 } \\
(\mathrm{mm})\end{array}$ & $\begin{array}{l}\text { Sürgün } \\
\text { Uzunluğu } \\
(\mathrm{cm})\end{array}$ \\
\hline Kontrol & $240 \mathrm{a}^{*}$ & $170 \mathrm{a}$ & $51.19 \mathrm{~b}$ & $48.27 \mathrm{~b}$ \\
Boğma & $242 \mathrm{a}$ & $175 \mathrm{a}$ & $57.41 \mathrm{a}$ & $51.49 \mathrm{a}$ \\
Pro-Ca & $257 \mathrm{a}$ & $180 \mathrm{a}$ & $60.40 \mathrm{a}$ & $47.90 \mathrm{~b}$ \\
\hline *Ayn
\end{tabular}

*Aynı sütunda aynı harf ile gösterilen ortalamalar arasındaki fark istatistiksel olarak önemsizdir $(\mathrm{p}<0.05)$.

Sürgün uzunluğu bakımından uygulamalar arasında istatistiksel olarak önemli bir farklıllk tespit edilmiştir $(\mathrm{p}<0.05)$. En yüksek sürgün boyu $51.49 \mathrm{~cm}$ ile boğma uygulamasında belirlenirken, en düşük ise $47.90 \mathrm{~cm}$ ile Pro-Ca uygulamasında belirlenmiştir (Çizelge 1). Medjdoub ve ark. (2004), elmada; Prive ve ark. (2004), elmada, Elfving ve ark. (2005), kirazda; Blanco ve ark. (2005), Fuji ve Royal Gala elma çeşitlerinde; Smit ve ark. (2005), armutta Pro-Ca uygulamasının sürgün gelişimini azalttı̆ğını tespit etmişlerdir. Pretorius ve ark. (2004), elmada; Sabanc1 ve Çağlar (2005), cevizde; Sousa ve ark. (2008) armutta; Alkan ve Seferoğlu (2014), bademde boğma uygulamasının sürgün gelişimini azalttığını tespit etmişlerdir. Çalışmada Pro$\mathrm{Ca}$ uygulamasından elde edilen bulgular araştırıcıların bulguları ile benzerlik gösterirken, boğma uygulamasından elde edilen bulgular ise farklılık göstermektedir.

Yaprak alt ve üst sıcaklık değerleri bakımdan uygulamalar arasındaki farklılık istatistiksel olarak önemli bulunmuştur $(\mathrm{p}<0.05)$. En düşük yaprak alt sıcaklığ $\mathrm{Pro}-\mathrm{Ca}$ uygulamasında $\left(22.5^{\circ} \mathrm{C}\right)$ belirlenirken, en yüksek ise kontrol uygulamasında $\left(24.0^{\circ} \mathrm{C}\right)$ belirlenmiştir. En düşük yaprak üst sıcaklığı $22.9^{\circ} \mathrm{C}$ ile Pro-Ca uygulamasında, en yüksek ise $24.5^{\circ} \mathrm{C}$ ile kontrol uygulamasında tespit edilmiştir (Çizelge 2).

Çizelge 2. Karayemişte farklı uygulamaların yaprak sıcaklığı ve yaprak klorofil miktarı üzerine etkisi (2015-2016 yılları ortalaması)

\begin{tabular}{cccc}
\hline Uygulama & $\begin{array}{c}\text { Yaprak Alt } \\
\text { Sicakllğ } 1 \\
\left({ }^{\circ} \mathrm{C}\right)\end{array}$ & $\begin{array}{c}\text { Yaprak Üst } \\
\text { Sicaklığ1 } \\
\left({ }^{\circ} \mathrm{C}\right)\end{array}$ & $\begin{array}{c}\text { Yaprak Klorofil } \\
\text { Miktarı (SPAD) }\end{array}$ \\
\hline Kontrol & $24.0 \mathrm{a}^{*}$ & $24.5 \mathrm{a}$ & $92.31 \mathrm{~b}$ \\
Boğma & $23.4 \mathrm{~b}$ & $23.9 \mathrm{~b}$ & $92.15 \mathrm{~b}$ \\
Pro-Ca & $22.5 \mathrm{c}$ & $22.9 \mathrm{c}$ & $98.88 \mathrm{a}$ \\
\hline
\end{tabular}

*Aynı sütunda aynı harf ile gösterilen ortalamalar arasındaki fark istatistiksel olarak önemsizdir $(\mathrm{p}<0.05)$. 
Pro-Ca ve boğma uygulaması ile yapilan çalışmalarda yaprak sıcaklığı ile alakalı herhangi bir bulguya rastlanmamıştır. Ancak Khang ve ark. (2010) Pro-Ca uygulamasının Çin lahanasında yaprak alanında azalmaya neden olduğunu ifade etmişlerdir. Bunun yanı sıra Kıran ve ark. (2016)'nın patlıcan bitkisinde farklı su seviyeleri ile yaptıkları çalışmada kontrol grubu (sulama yapılmayan) bitkilerinde yaprak alanının daha fazla olduğunu tespit etmişlerdir. Ayrıca Külahçılar (2017) findıkta farklı su kısitlılığı uygulamasında kontrol bitkilerinin (sulama yapılmayan) yaprak sıcaklığının daha yüksek olduğunu ifade etmiştir. Nitekim yürütülen bu araştırmalarda yaprak alanının azalışına bağlı olarak sıcaklığın daha düşük olduğu gözlemlenmiştir. Bu bağlamda çalışmamızda Pro-Ca ile muamele olmuş bitkilerde yaprak alanının azalması, yaprak sıcaklığının azalışına neden olmuş olabilir.

Yaprak klorofil miktarı bakımından uygulamalar arasında istatistiksel olarak önemli bir farkl1l1k belirlenmiş̧ir $(p<0.05)$. En yüksek yaprak klorofil miktarı Pro-Ca uygulamasında (98.88 SPAD) ölçülürken, en düşük ise boğma uygulamasında (92.15 SPAD) ölçülmüştür (Çizelge 2). Khang ve ark. (2010), Çin lahanasında, Dragisic-Maksimovic ve ark. (2017) ahudududa, Sekhar ve ark. (2018) çilekte Pro-Ca uygulamasında kontrole göre daha yüksek klofil miktarı tespit etmişlerdir. Alkan ve Seferoğlu (2014) bademde yaptığ çalışmada kontrole göre boğma uygulamasında daha düşük klorofil miktarı tespit etmiştir. Khang ve ark. (2010) Pro-Ca uygulamasının giberellin sentezini engelleyerek, yaprak boyutunun azalmasina ve bu süreçte yaprakta biriken klorofil miktarının artmasına neden olduğunu ifade etmişlerdir. $\mathrm{Bu}$ bakımdan çalışmamızda Pro-Ca ile muamele olmuş bitkilerin klorofil miktarının yüksek olmasının, Pro-Ca'nın yaprak boyutunda azalmaya neden olmasindan kaynaklı olabileceği düşünülmektedir.

\section{Sonuç}

Sonuç olarak, karayemişte bazı bitkisel özellikler üzerine boğma ve Pro-Ca uygulamalarının çalışmada genel olarak diğer uygulamalara göre Pro-Ca uygulamasının sürgün gelişimi sınırlandırması ve yaprak klorofil miktarında artışa neden olması bakımından ön plana çıktığı belirlenmiştir.

\section{Teşekkür}

Bu çalışma Ordu Üniversitesi Bilimsel Araştırmalar Koordinasyonu Birimi tarafindan AR-1310 nolu proje ile desteklenmiştir.

\section{Kaynaklar}

Ağca, Z., 2008. Pro-Ca (Prohexadione-Calcium) uygulamasının bazı bodur meyve türlerinde ağaç gelişimi ve meyve özellikleri üzerine etkisi. Yüksek Lisan Tezi, Kahramanmaraş Sütçü İmam
Üniversitesi, Fen Bilimleri Enstitüsü, Kahramanmaraş.

Akbulut, M., Macit, İ., Ercisli, S., Koc, A, 2007. Evaluation of 28 cherry laurel (Laurocerasus officinalis) genotypes in the Black Sea region, Turkey. New Zealand Journal of Crop And Horticultural Science, 35 (4): 463-465.

Alkan, G., Seferoğlu, HG., 2014. Bazı badem çeşitlerinin Aydın ekolojisindeki fenolojik ve morfolojik özellikleri. Meyve Bilimi, 1(2): 38-44.

Ansin, Z., Özkan, Z.C., 1998. Prunus laurocerasus L. In: Spermatophyta. Karadeniz Teknik Üniversitesi, Orman Fakültesi, Genel Yayın No. 167, Fakülte Yayın No:19, 512s., Trabzon.

Bastas, K.K., Maden, S., 2004. Ateş yanıklığı (Erwinia amylovora (BURR..) WINSLOW et al.)'nın prohexadione-ca (BAS $125 \quad \mathrm{~W}$ ) ve benzothiadiazole+metalaxyl (BION MX44 WG) ile savaşımı üzerinde araştırmalar. Süleyman Demirel Üniversitesi Ziraat Fakültesi Dergisi, 18(33): 49-58.

Blanco, A., Medjdoub, R., Val, J., 2005. Inhibition of vegetative growth in red apple cultivars using prohexadione-calcium. Journal of Horticultural Science and Biotechnology, 80(2): 263-271.

Bostan, S.Z., İslam, A., 2003. Pomological and phenological traits of local cherry laurel (Prunus laurocerasus L.) types grown in Trabzon province of Turkey. The Journal of Agricultural Faculty of Ondokuz Mayis University, 18 (1): 27-31.

Costa, G., Sabatini, E., Spinelli, F., Andreotti, C., Spada, G., Mazzini, F., 2004. Prohexadione-ca controls vegetative growth and cropping performance in pear. Acta Horticulturae, 653: 127132.

Çağlar, S., Ağca, Z., 2009. Pro-Ca (ProhexadioneCalcium) uygulamasının Mondial Gala/M9 elma ağaçlarının gelişimi ve bazı meyve özellikleri üzerine etkisi. Tarım Bilimleri Araştırma Dergisi, (2): 101-106.

Çetinbaş, M., Butar, S., Atasay, A., İşçi, M., Koçal, H., 2014. The Effect of Pro-Ca (Prohexadione Calcium) application on the shoot growth and fruit characteristics of 'Scarlet spur cv.' Apple. $25^{\text {th }}$ International Scientific-Experts Congress on Agriculture and Food Industry - Izmir, 265-268.

Dragisic-Maksimovic, J.J., Poledica, M.M., Radivojević, D.D., Milivojevic, J.M., 2017. Enzymatic profile of ' Willamette' raspberry leaf and fruit affected by Prohexadione-Ca and young canes removal treatments. Journal of Agricultural and Food Chemistry, 65(24): 5034-5040.

Elfving, D.C., Lang, G.A., Visser, D.B., 2005. Effects of Prohexadione-Calcium and Ethephon on growth and flowering of 'Bing' sweet cherry. Acta Horticulturae, 667: 439-446.

Evans, R.R., Evans, R.E., Rademacher, W., 1997. Prohexadione-Calcium for suppression of vegetative growth in Eastern Apples. Acta Horticulturae, 451:663-666. 
Hekimci, B., 2014. İncir (Ficus carica cv." Bursa siyahı") fidanlarında farklı uygulamaların bodurlaştırma üzerine etkisi. Yüksek Lisans Tezi. Adnan Menderes Üniversitesi Fen Bilimleri Enstitüsü, Aydın.

İslam, A., 2005. Karayemiş yetiştiriciliği ve önemi. Ege Karadeniz Dergisi, 28(4): 25-32.

İslam, A., Çelik, H., Aygün, A., Kalkışım, Ö., 2010. Selection of native cherry laurels (Prunus laurocerasus L.) in the Blacksea Region. International Conference on Organic Agriculture in Scope of Environmental Problems 03-07 February 2010, Famagusta, 15-16.

İslam, A., Deligöz, H., 2012. Ordu ilinde karayemiş (Laurocerasus officinalis L.) seleksiyonu. Akademik Ziraat Dergisi, 1(1): 37-44.

Kang, S.M., Kim, J.T., Hamayun, M., Hwang, IC., Khan, A.L., Kim, Y.H., Lee, I.J., 2010. Influence of prohexadione-calcium on growth and gibberellins content of Chinese cabbage grown in alpine region of South Korea. Scientia Horticulturae, 125(2): 8892.

Karadeniz, T., Kalkisim, O., 1996. Investigations on selection of cherry laurel (Prunus laurocerasus L.) grown in Akcaabat. Journal of Yuzuncuy1l University Agricultural Faculty, 6(1): 147-153.

Kıran, S., Kuşvuran, Ş., Özkay, F., Ellialtıŏglu, Ş., 2016. Tuza tolerant ve hassas patlican genotiplerinin kuraklık stresi koşullarında bazı morfolojik özelliklerinde meydana gelen değişimler. Mustafa Kemal Üniversitesi Ziraat Fakültesi Dergisi, 21(2): 130-138.

Külahçılar, A., 2017. Tombul fındık çeşidinde mini yağmurlama sulama yönteminde farklı su seviyesi uygulamalarının verim ve kaliteye etkisi. Yüksek Lisan Tezi. Ordu Üniversitesi Fen Bilimleri Enstitüsü, Ordu.

Macit, I., Demirsoy, H., 2012. New promising cherry Laurel (Prunus laurocerasus L.) genotypes in Turkey. Bulgarian Journal of Agricultural Science, 18(1): 77-82.

Medjdoub, R., Val, J., Blanco, A., 2004. Prohexadione$\mathrm{Ca}$ inhibits vegetative growth of 'Smoothee Golden Delicious' apple trees. Scientia Horticulturae, 101(3): 243-253.

Özçağıran, R., 1974. Meyve ağaçlarında anaç ile kalem arasındaki fizyolojik ilişkiler. Ege Üniversitesi, Ziraat Fakültesi Yayınları, No:243, 45s., Bornova.
Pearce, S.C., 1975. Field experimentation with fruit trees and other perennial plants. Technical Communication, No. 23. C. A. B., London, U. K. $182 \mathrm{~s}$.

Pretorius, J.JB., Wand, S.J.E., Theron, K.I., 2004. Fruit and shoot growth following combined girdling and thinning of 'Royal Gala' apple trees. In XXVI International Horticultural Congress: Key Processes in the Growth and Cropping of Deciduous Fruit and Nut Trees, 636: 401-407.

Prive, J.P., Cline, J., Nichols, D., Fava, E., Embree, C., Byl, M., 2004. Preliminary results on the efficacy of apple trees treated with the growth retardant prohexadione-calcium (Apogee $\AA$ ) in Eastern Canada. Acta Horticulturae, 636: 137-144.

Rufato, L., Machado, B.D., Luz, A.R., Marcon Filho, J.L., Hipólito, J.S., Kretzschmar, A.A., 2014. Effect of trunk girdling on growth and crop yield of' packham's triumph'pear. In XII International Pear Symposium, 1094: 265-268.

Sabancı, A., Çağlar, S., 2005. Cevizlerde kuşaklı boğma uygulaması üzerine bir araştırma. Kahramanmaraş Sütçü İmam Üniversitesi Fen ve Mühendislik Dergisi, 8(2): 135-139.

Sekhar, R.S., Mehta, K., Kundu, S., Ghosh, B., 2018. Effect of growth regulators on physiological parameters of strawberry (Fragaria $\mathrm{x}$ ananassa Duch.) cv. Chandler. International Journal of Current Microbiology and Applied Sciences, 7(4): 2423-2428.

Smit, M., Meintjes, J.J., Jacobs, G., Stassen, P.J.C., Theron, K.I., 2005. Shoot growth control of pear trees (Pyrus Communis L.) with ProhexadioneCalcium. Scientia Horticulturae, 106: 515-529.

Sousa, R.M., Calouro, F., Oliveira, C.M., 2007. Influence of trunk girdling on growth and fruit production of 'Rocha'/BA29. In X International Pear Symposium, 800: 319-324.

Westwood, M.N., 1978. Temperate zone pomology. W. H. Freeman and Co., Sanfransisco, USA., 428 s. 